Article

\title{
Eco-Friendly Cotton/Linen Fabric Treatment Using Aqueous Ozone and Ultraviolet Photolysis
}

\author{
Kengo Hamada ${ }^{1, *} \mathbb{0}$, Tsuyoshi Ochiai ${ }^{1,2}{ }^{\oplus}$, Yasuyuki Tsuchida ${ }^{3}$, Kyohei Miyano ${ }^{4}$, \\ Yosuke Ishikawa ${ }^{4}$, Toshinari Nagura ${ }^{4}$ and Noritaka Kimura ${ }^{3}$ \\ 1 Kawasaki Technical Support Department, Local Independent Administrative Agency Kanagawa Institute of \\ Industrial Science and Technology (KISTEC), Kanagawa 213-0012, Japan; pg-ochiai@newkast.or.jp \\ 2 Photocatalysis International Research Center, Tokyo University of Science, 2641 Yamazaki, Noda, \\ Chiba 278-8510, Japan \\ 3 Department of Bioengineering, Nagaoka University of Technology, Niigata 940-2188, Japan; \\ 2dedeenn6@gmail.com (Y.T.); nkimura@vos.nagaokaut.ac.jp (N.K.) \\ 4 Business Strategy Department, Nisshinbo Textile Inc., Tokyo 103-8650, Japan; \\ miyanokyohei@nisshinbo.co.jp (K.M.); ishikawa@nisshinbo.co.id (Y.I.); t.nagura@nisshinbo.co.jp (T.N.) \\ * Correspondence: k-hamada@kistec.jp; Tel.: +81-44-819-2105
}

Received: 30 September 2020; Accepted: 28 October 2020; Published: 2 November 2020

\begin{abstract}
Chemicals for the scouring and bleaching of fabrics have a high environmental load. In addition, in recent years, the high consumption of these products has become a problem in the manufacture of natural fabric products. Therefore, environmentally friendly, low-waste processes for fabric treatment are required. In this paper, we discuss the bleaching of fabrics using advanced oxidation processes (AOP). These processes use electrochemically generated aqueous ozone and ultraviolet (UV) irradiation to achieve bleaching. However, colour reversion often occurs. In this study, we suppressed unwanted colour reversion by treatment with rongalite. After treatment, changes in fabric colour were determined by measuring the colour difference and reflectance spectra. The best bleaching effect was obtained when ozone and UV irradiation treatments were combined, achieving results similar to those of a conventional bleaching method after 60 min of UV irradiation. In addition, the AOP treatment resulted in the simultaneous scouring of the fabric, as shown by the increased hydrophilicity of the fabric after AOP treatment. Thus, this AOP process represents a new fabric bleaching process that has an extremely low environmental impact.
\end{abstract}

Keywords: advanced oxidation processes; ozone; ultraviolet; bleaching; fabrics

\section{Introduction}

In the manufacture of natural fabric products, such as cotton and linen, alkaline chemicals and surfactants are used to remove contaminants (i.e., scouring). In addition, to bleach coloured components derived from natural products, an aqueous solution of sodium hypochlorite or heat treatment is used (i.e., bleaching) [1]. Therefore, the manufacture of natural fibre products is energy intensive, and the environmental load is high, especially because of the need for subsequent wastewater treatment [2-4]. An alternative to conventional bleaching with chemicals is advanced oxidation processes (AOP), which combine the treatment of hydrogen peroxide or aqueous ozone generated by electrolysis [5-9] with irradiation by ultraviolet (UV) light [10-12] and oxidation treatment using enzymes or microwave heating $[13,14]$. These methods do not use environmentally persistent agents and have low energy costs. In addition, oxidative bleaching with AOP allows the omission of the refining step used in conventional methods, again resulting in a more environmentally friendly method. However, after oxidative bleaching by AOP, the whiteness of the fabric deteriorates (colour reversion), 
especially during heating (ironing) after bleaching. Therefore, oxidative bleaching by AOP requires further optimisation.

In this study, we developed a bleaching technology with a low environmental load that combines aqueous electrochemically generated ozone and UV irradiation for the combined bleaching and scouring of cotton and linen. Changes in fabric colour were observed by measuring the colour difference and reflectance spectroscopy. The $\mathrm{OH}$ radicals generated by UV irradiation decompose the coloured components derived from natural products [15,16]; a chemical probe method $[17,18]$ was used to estimate the amount of $\mathrm{OH}$ radicals generated from ozone by UV irradiation to understand the bleaching mechanism. Moreover, we proposed a reduction treatment with rongalite, a common reducing agent used in the textile industry, to suppress colour reversion after bleaching, which succeeded in minimising the colour reversion after ironing. Our method has excellent bleaching properties and extremely low environmental impact; thus, this method could replace conventional scouring and bleaching methods.

\section{Results}

\subsection{Fabric Bleaching Using Aqueous Ozone under UV Irradiation}

Figure 1a shows the relationship between processing time and the colour of cotton samples. For comparison, three types of treatment were performed: aqueous ozone $+\mathrm{UV}$, aqueous ozone, and water + UV. The colour difference values decreased over time in all treatments. The treatment combining aqueous ozone and UV showed the greatest change, followed by those with aqueous ozone and water $+\mathrm{UV}$. In addition, the change in colour difference was approximated as a first-order reaction, and the reaction rate constant was obtained (Figure $1 b$ ). The reaction rate constants for aqueous ozone + UV, aqueous ozone, and water + UV were $0.029,0.015$, and 0.009 , respectively.
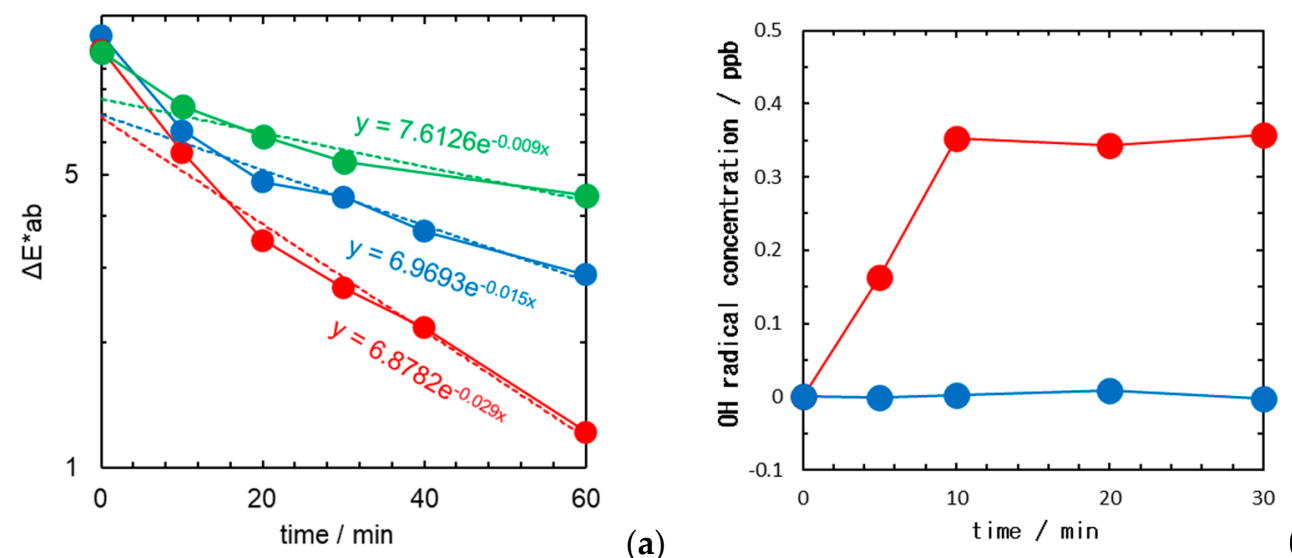

(a)

Figure 1. (a) Relationship between treatment time and colour difference ( $\Delta E^{*} a b$ values are with respect to the colour of cotton bleached using a conventional chemical method) for each bleaching method (red: aqueous ozone + ultraviolet (UV), blue: aqueous ozone, green: water + UV). (b) Relationship between treatment time and $\mathrm{OH}$ radical concentration (red: aqueous ozone with UV, blue: aqueous ozone without UV).

The changes in the $\mathrm{OH}$ radical concentration were determined using a chemical probe fluorescence method. Figure $1 \mathrm{~b}$ shows the relationship between the treatment time and $\mathrm{OH}$ radical concentration. No change in the $\mathrm{OH}$ radical concentration was observed in the aqueous ozone treatment without UV irradiation. In contrast, in the aqueous ozone treatment, the concentration of $\mathrm{OH}$ radicals increased with UV irradiation and became constant $10 \mathrm{~min}$ after the start of irradiation.

The changes in fabric colour were quantified using reflectance spectroscopy measurements. Figure 2 shows the reflectance spectra of cotton samples treated by AOP and conventional chemical bleaching for different periods. In the AOP-treated samples, the reflectance increased in the region 
below $550 \mathrm{~nm}$ with time, and a spectrum equivalent to that of the cotton fabrics bleached by the conventional method was achieved $60 \mathrm{~min}$ after the start of UV irradiation. Figure 3 shows photographs of the fabrics before bleaching, after AOP treatment for $60 \mathrm{~min}$, and after conventional bleaching. The cotton fabrics before bleaching had a dull yellow colour. The cotton fabrics treated by AOP had a similar whiteness to that of the cotton bleached by the conventional method.

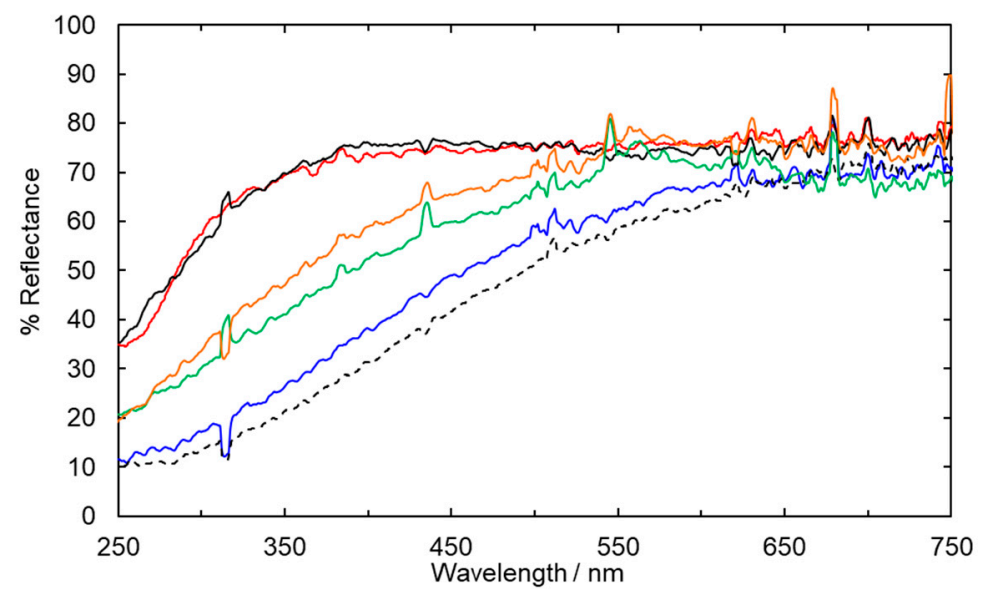

Figure 2. Reflectance spectra of cotton samples treated by advanced oxidation processes (AOP) for different periods (black dots, blue, green, yellow, and red indicate 0, 15, 30, 45, and $60 \mathrm{~min}$, respectively) and conventional chemical bleaching (black).

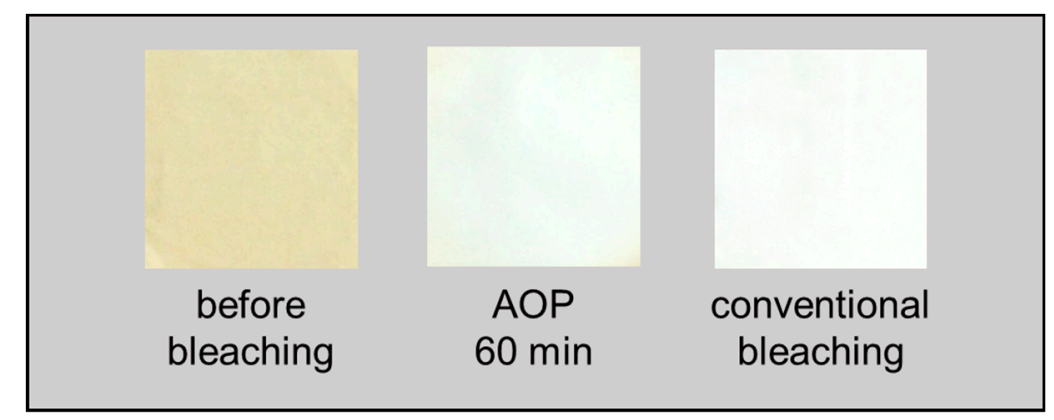

Figure 3. Photographs of the cotton samples before bleaching, after advanced oxidation processes (AOP) treatment for $60 \mathrm{~min}$, and after conventional bleaching.

Figure 4 shows the reflectance spectra of linen samples treated using each bleaching treatment, as well as conventional chemical bleaching. The treatment with the combination of aqueous ozone and UV resulted in the largest increase in reflectance, followed by those with aqueous ozone and water + UV. Similar to that of the cotton samples, the percentage reflectance of the linen samples after AOP treatment increased. Notably, the samples treated by AOP for 120 min had improved reflectance over the conventional fabric.

Figure 5 shows photographs of the linen samples after bleaching treatment. The fabric before bleaching was grey. The bleaching process occurred in the centre, where UV irradiated aqueous ozone was in direct contact with the fabric. The linen fabrics treated with AOP for $120 \mathrm{~min}$ showed whiteness similar to that of the conventional method in the central spot. 


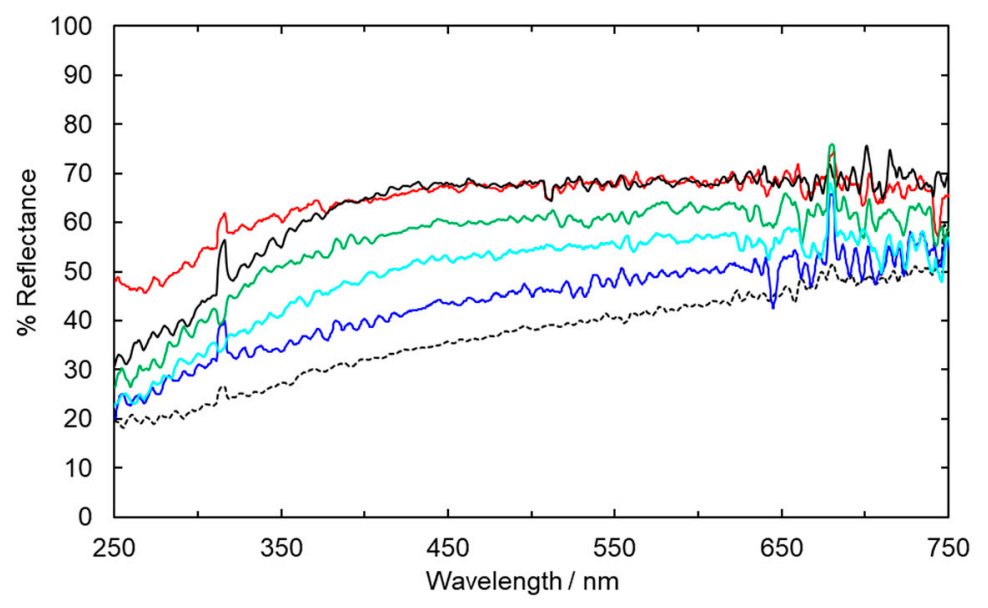

Figure 4. Reflectance spectra of linen samples treated by conventional chemical bleaching (black), no treatment (black dot), water + UV treatment for $60 \mathrm{~min}$ (blue), ozone water treatment for $60 \mathrm{~min}$ (light blue), AOP treatment for $60 \mathrm{~min}$ (green), and AOP treatment for $120 \mathrm{~min}$ (red).

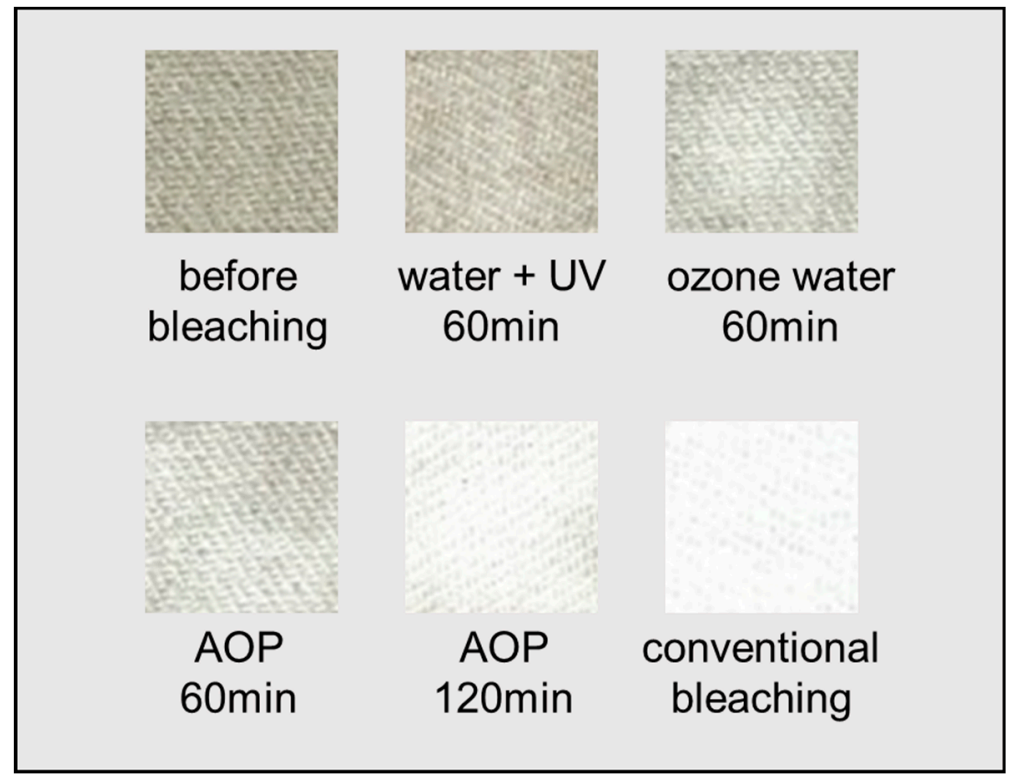

Figure 5. Photographs of the linen samples before bleaching, after water + ultraviolet (UV) treatment for $60 \mathrm{~min}$, after aqueous ozone treatment for $60 \mathrm{~min}$, after advanced oxidation processes (AOP) treatment for $60 \mathrm{~min}$, after AOP treatment for $120 \mathrm{~min}$, and after conventional bleaching.

Figure 6 shows the effect of AOP treatment on the fabric samples. The percentage reflectance increased in the region below $550 \mathrm{~nm}$ with and without scouring. The change in the reflectance spectrum of the cotton cloth was constant regardless of whether it was scoured. In addition, Figure 7 (left) shows a photograph of a drop of water on a cotton sample before scouring. Figure 7 (right) shows a photograph of a wetted fabric sample after bleaching by AOP treatment for $30 \mathrm{~min}$. Before scouring and bleaching, the fabric was water repellent. After AOP treatment for $30 \mathrm{~min}$, the cotton lost its water repellence, and the water drop penetrated the fabric. 


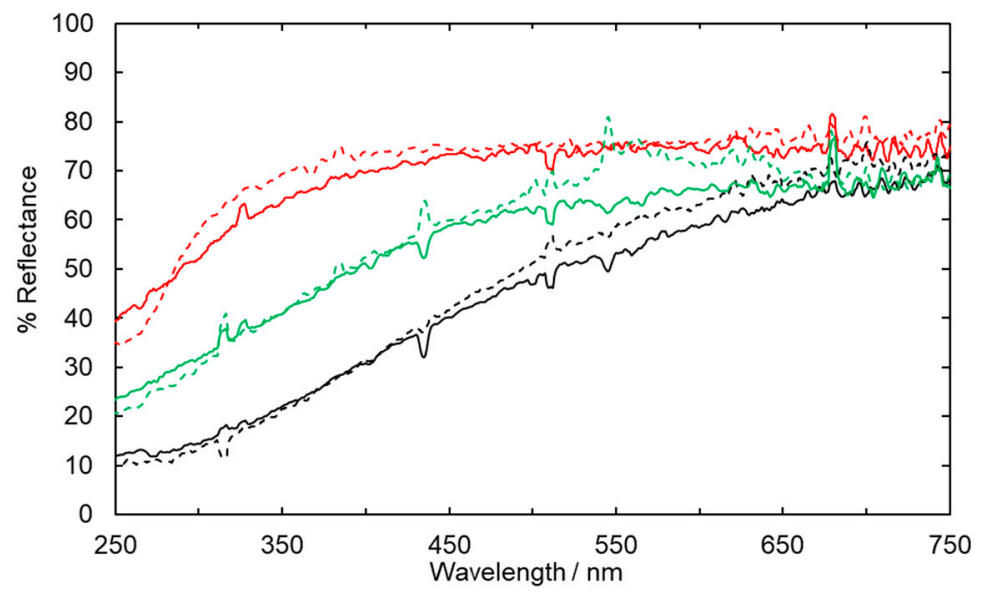

Figure 6. Reflectance spectra of the cotton samples after advanced oxidation processes (AOP) treatment for different periods (black, green, and red indicate 0, 30, and 60 min AOP treatment, respectively) with (dots) and without (solid line) scouring.

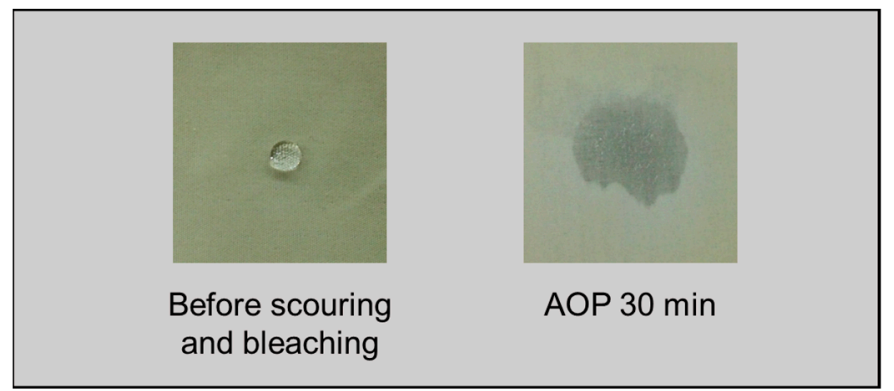

Figure 7. Photographs of cotton samples before scouring and bleaching and after advanced oxidation processes (AOP) treatment for $30 \mathrm{~min}$ treated with a drop of water.

Figure 8 shows the reflectance spectra of AOP-treated samples ( 0 and $60 \mathrm{~min})$ before and after ironing at $200{ }^{\circ} \mathrm{C}$. When the cotton was dried after AOP treatment, the reflectance decreased below $500 \mathrm{~nm}$. When the ironed fabric was again subjected to AOP treatment, the spectrum was restored to the pre-ironing state. Ironing and AOP treatment were repeated five times, but only the results of the second ironing/AOP cycle are shown in Figure 8. The colour of the fabric changed from yellowish white to white and back after each of the five ironing/AOP cycles.

\subsection{Suppression of Colour Reversion Using Rongalite Treatment}

Figure 9 shows the reflectance spectra of cotton samples with and without rongalite treatment. The reflectance spectrum of the cotton fabric subjected to AOP treatment for 60 min increased with respect to that of the untreated sample. The reflectance spectrum of the cotton fabric ironed after AOP treatment decreased below $550 \mathrm{~nm}$. On the other hand, the cotton fabric ironed after rongalite treatment did not show a decrease in the reflectance spectrum below $550 \mathrm{~nm}$, and the reflectance spectra were maintained after AOP treatment. Figure 10 shows photographs of the cotton fabrics after AOP for $60 \mathrm{~min}$, after ironing at $200^{\circ} \mathrm{C}$, and after ironing at $200^{\circ} \mathrm{C}$ following rongalite treatment. The cotton sample after AOP was white. The cotton sample after ironing was not as white as that treated by AOP alone. The cotton sample after rongalite treatment and ironing was as white as that after AOP alone. 


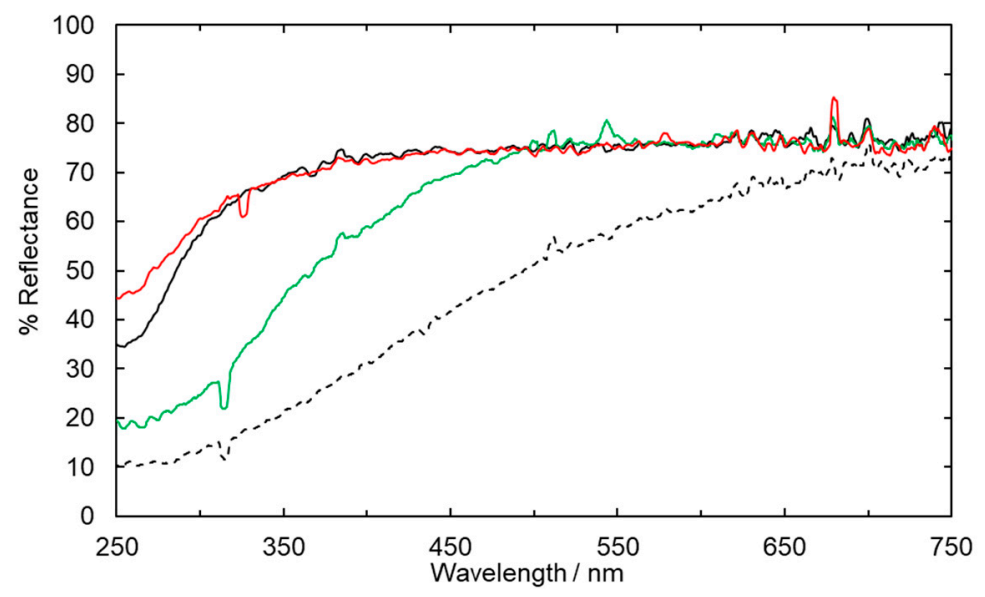

Figure 8. Reflectance spectra of cotton samples before (black dots) and after (black line) advanced oxidation processes (AOP) for $60 \mathrm{~min}$, colour reversion after ironing at $200{ }^{\circ} \mathrm{C}$ (green), and after a second AOP treatment 15 min after ironing (red).

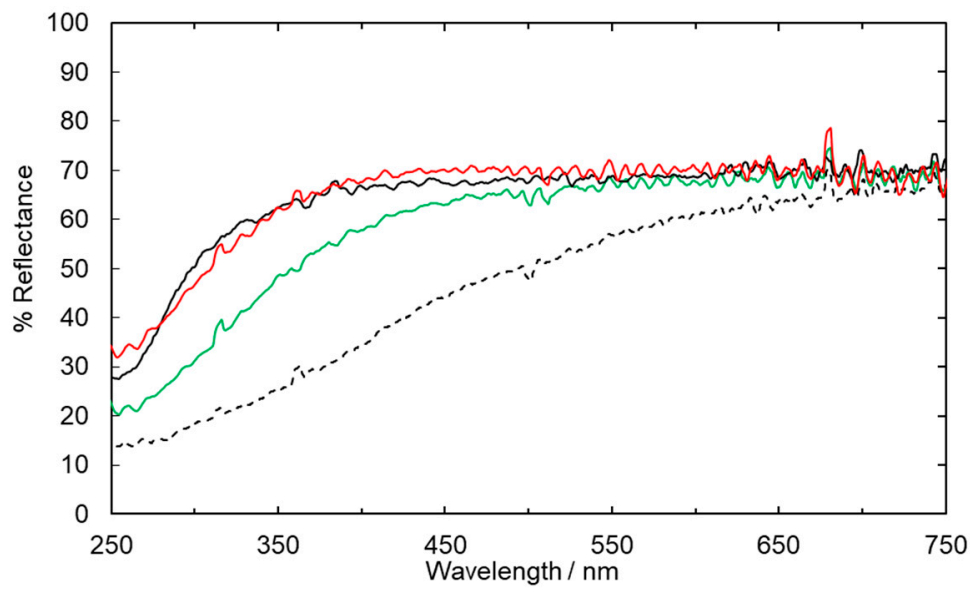

Figure 9. Reflectance spectra of cotton samples before (black dots) and after (black line) advanced oxidation processes (AOP) for $60 \mathrm{~min}$ and those of samples ironed at $200{ }^{\circ} \mathrm{C}$ with (red) and without (green) rongalite treatment.

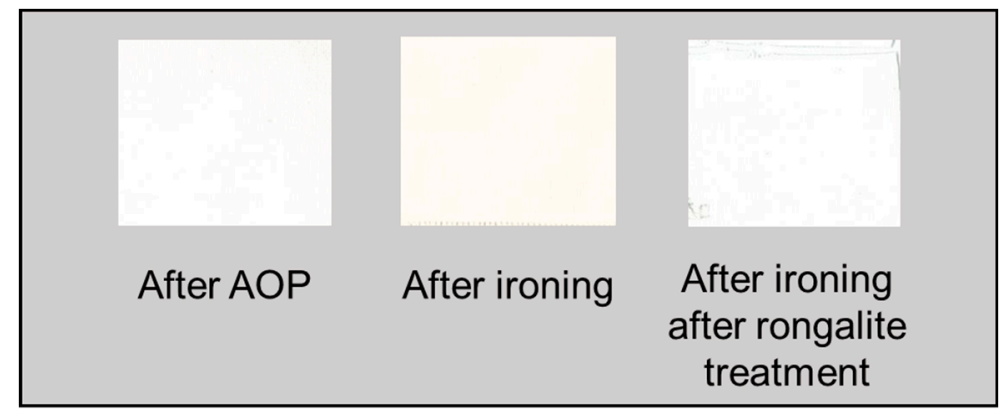

Figure 10. Photographs of cotton samples after advanced oxidation processes (AOP) for $60 \mathrm{~min}$, after ironing at $200{ }^{\circ} \mathrm{C}$, and after ironing at $200^{\circ} \mathrm{C}$ following rongalite treatment.

Figure 11 shows the reflectance spectra of linen samples with and without rongalite treatment. The percentage reflectance of the linen fabrics subjected to AOP treatment for 120 min increased compared with that of the untreated sample. The reflectance spectrum of the linen fabric ironed after AOP treatment decreased at all wavelengths. In contrast, the cotton fabric ironed after rongalite treatment did not show a decrease, and the reflectance spectra were maintained after AOP treatment. 
Figure 12 shows photographs of the linen fabrics after AOP for $120 \mathrm{~min}$ and after ironing at $200{ }^{\circ} \mathrm{C}$, with and without rongalite treatment. The linen sample after AOP was white, but, after ironing, some whiteness was lost. After rongalite treatment and ironing, the sample remained as white as the sample after AOP alone.

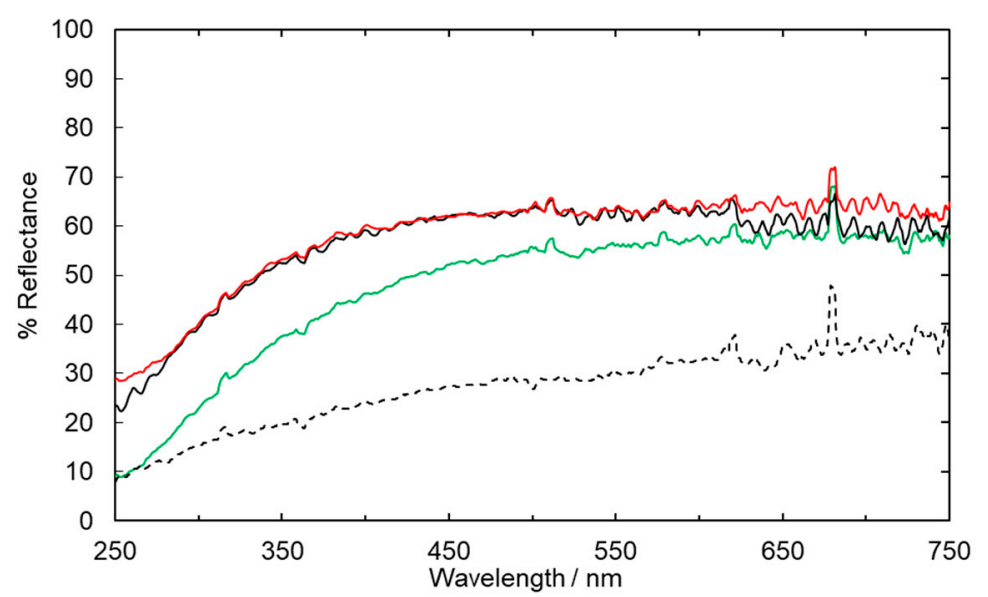

Figure 11. Reflectance spectra of linen samples without advanced oxidation processes (AOP; black dots) and after AOP for 120 min (black line) and of AOP-treated samples after ironing at $200{ }^{\circ} \mathrm{C}$ without (green) and with (red) rongalite treatment.

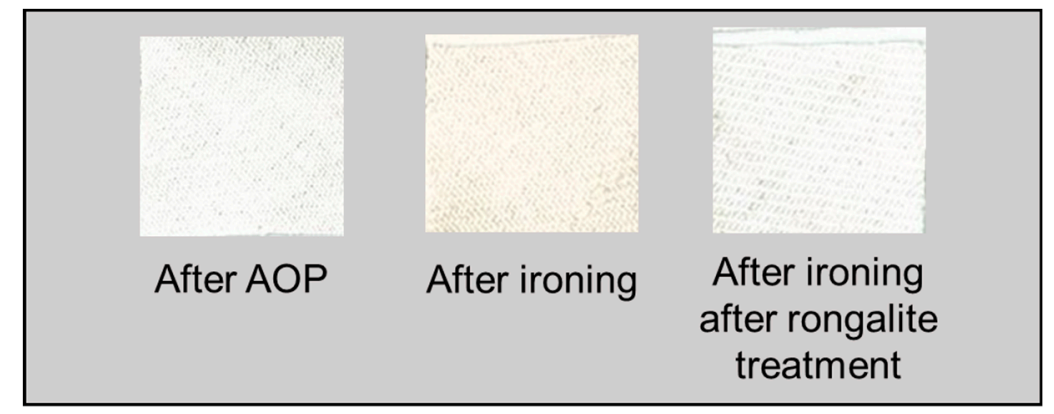

Figure 12. Photographs of the linen samples after advanced oxidation processes (AOP) for $120 \mathrm{~min}$, after AOP and ironing at $200{ }^{\circ} \mathrm{C}$, and after AOP and ironing at $200{ }^{\circ} \mathrm{C}$ following rongalite treatment.

\section{Discussion}

Figure 1a shows that the combination of aqueous ozone and UV light was most suitable for bleaching, although a bleaching effect was also obtained when using aqueous ozone alone and water + UV. Moreover, the reaction rate constant of the aqueous ozone + UV system was not a simple sum of those of the aqueous ozone and water + UV systems. Therefore, it appears that the cotton was bleached by the synergistic effect of ozone and UV irradiation. Figure $1 \mathrm{~b}$ shows that $\mathrm{OH}$ radicals were generated by UV irradiation of the aqueous ozone. It is known that $\mathrm{OH}$ radicals decompose coloured components in fabrics during AOP $[19,20]$, and the generation of $\mathrm{OH}$ radicals is likely responsible for the high reaction constant shown in Figure 1a. Specifically, excited singlet oxygen is produced by the UV irradiation of ozone at $310 \mathrm{~nm}$, whereas excited triplet oxygen is produced by the visible light irradiation of ozone $(>460 \mathrm{~nm})$. The bleaching $\mathrm{OH}$ radicals are generated from excited singlet oxygen [21]. Disodium terephthalate (NaTA) can be used as an indicator of the generated $\mathrm{OH}$ radicals, forming 2-terephthalic acid in the process [17]; approximately $0.35 \mathrm{ppb} \mathrm{OH}$ radicals were produced by UV irradiation. $\mathrm{OH}$ radicals are extremely reactive [22]; thus, their lifetime is very short. For these reasons, the $\mathrm{OH}$ radical concentration in Figure $1 \mathrm{~b}$ is low, compared with the ozone concentration.

Figures 2 and 3 show that the AOP treatment that combined aqueous ozone and UV (60 min) had the same bleaching effect as the conventional method. As unbleached cotton contains coloured 
components, it had a low reflectance spectrum below $550 \mathrm{~nm}$. Cotton contains approximately $90 \%$ cellulose and approximately $10 \%$ non-cellulosic matter, comprising proteins, waxes, pectin, and ash [1]. Therefore, on the basis of the results, these components were decomposed by AOP treatment to the same extent as in the conventional bleaching method. The linen before bleaching also contained coloured components, like cotton, and the low reflectance spectrum of the unbleached linen shown in Figure 4 is due to these components. As shown in Figures 4 and 5, in the case of linen, it took $120 \mathrm{~min}$ of AOP to bleach to the same extent as the conventional method. Thus, bleaching time is dependent on the amount of coloured components contained in the linen. Unlike cotton, linen contains only $\sim 70 \%$ cellulose and a high proportion of non-cellulosic matter, which complicates the bleaching process. In addition, non-cellulosic matter contains a small amount of dark-coloured lignin [23], which suggests that linen will require a longer treatment time. As shown in Figure 6, AOP-treated cotton fabrics without scouring were bleached to the same degree as those with scouring and AOP treatment. In addition, Figure 7 shows that AOP treatment eliminated the water repellence of the cotton fabrics observed before scouring, resulting in hydrophilicity. As previously mentioned, before scouring, cotton contains wax [1], which yields water repellence. Therefore, the results in Figures 6 and 7 suggest that AOP treatment removes both coloured compounds and residual components (wax and oil) simultaneously. Thus, unlike conventional processes, our AOP process achieves scouring and bleaching at the same time.

In Figure 8, the colour return after the AOP process is shown by the reflectance spectra. In particular, the reflectance of the ironed sample was reduced, compared with that of the sample after AOP treatment. However, the reflectance recovered again after AOP treatment following ironing. However, repeated ironing resulted in the appearance of colour. The ironing and AOP treatment were repeated five times, but only the second cycle is shown in Figure 8. These results suggest that the colour reversion after ironing and AOP treatment is a reversible reaction. Cellulose, the main component of cotton, can be oxidised, and the oxidised form shows absorption in the near-UV to visible light region [24]. Even after AOP treatment, the cellulose in cotton may be oxidised, resulting in colour reversion. Therefore, in this study, rongalite, a reducing agent, was used to suppress colour reversion after AOP treatment and ironing. As shown in Figures 9 and 10, without rongalite treatment, reflectance decreased after ironing, whereas rongalite-treated fabrics did not show a decrease in reflectance in the wavelength region below $500 \mathrm{~nm}$, even after ironing. In addition, even in the case of linen, rongalite-treated fabrics did not show a decrease in reflectance after ironing; the reflectance spectra after AOP treatment were similar to those before treatment (Figures 11 and 12).

Figure 13 shows the proposed mechanisms of colour reversion and suppression of colour reversion after rongalite treatment of fabrics. AOP treatment could damage the fabric [12,25], and previous studies on the cause of colour reversion after oxidative bleaching have reported that some of the $\mathrm{OH}$ groups of cellulose (particularly those at the 2 nd and 3rd positions) are oxidised, resulting in the formation of $\mathrm{C}=\mathrm{O}$ groups and some conjugated double bonds [24]. Thus, colour reversion could be suppressed by the reduction of the $\mathrm{C}=\mathrm{O}$ groups generated in the cellulose fibres of $\mathrm{OH}$ groups after bleaching. Therefore, before ironing, the AOP-treated fabric was treated with a strongly reducing rongalite solution to reduce the $\mathrm{C}=\mathrm{O}$ groups. Consequently, subsequent heat treatment (ironing) did not result in the formation of conjugated double bonds. 


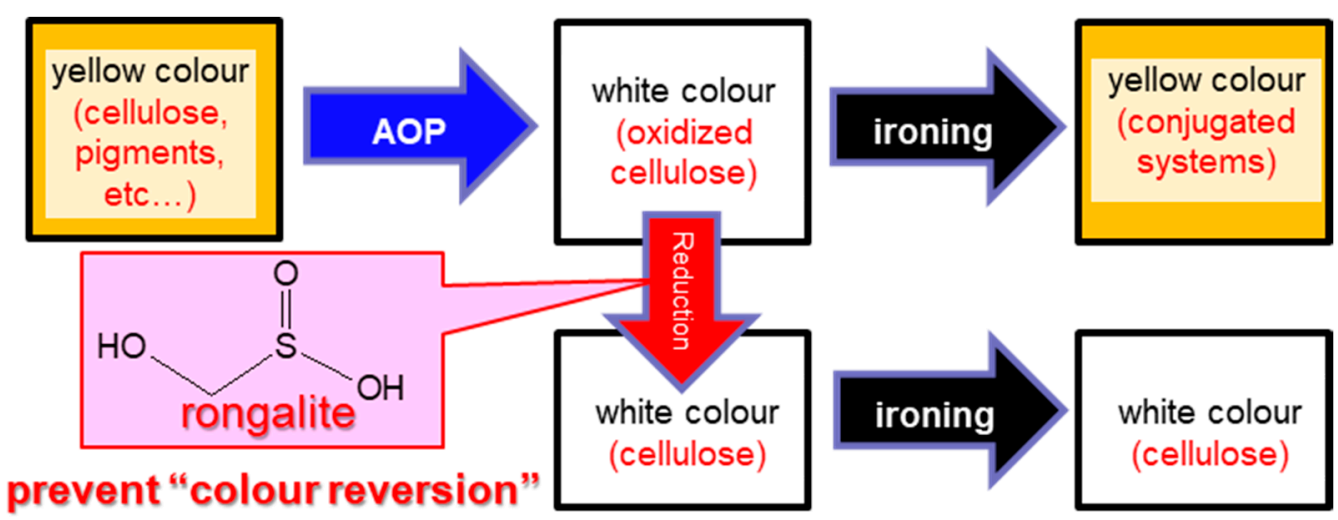

Figure 13. Proposed mechanisms of the suppression of colour reversion in fabrics and the effect of rongalite treatment.

\section{Materials and Methods}

Cotton and linen cloths were provided by Nisshinbo Textrail Co., Ltd. (Tokyo Japan). The colour differences of the fabrics were measured using a colour reader (CR-10, Konica Minolta Japan, Inc., Tokyo, Japan) and expressed as $L^{*} a^{*} b^{*}$ and $\Delta E^{*} a b$ values [26,27]. Here, $L^{*}$ represents brightness, equalling zero for a black diffuser and 100 for a perfectly reflecting one; $a^{*}$ represents colour on the red-green axis, being positive for red and negative for green; and $b^{*}$ represents colour on the blue-yellow axis, being positive for yellow and negative for blue. The colour difference was calculated as $\Delta E^{*} a b=\left(\left(\Delta L^{*}\right)^{2}+\left(\Delta a^{*}\right)^{2}+\left(\Delta b^{*}\right)^{2}\right)^{1 / 2}$, where $\Delta L^{*}$ is the difference in brightness between two vivid surfaces and $\Delta a^{*}$ and $\Delta b^{*}$ are the differences in the colour coordinates $a^{*}$ and $b^{*}$, respectively. Figure 14 shows the bleaching experiment in which aqueous ozone and UV irradiation were combined. UV light is emitted above a cloth sample placed on a glass plate. As a UV light source, an LA-310UV manufactured by Hayashi Clock Industry Co., Ltd. (Tokyo, Japan) was used. In addition, the electrolytically generated aqueous ozone was produced by an aqueous ozone generator (Quick $\mathrm{O}_{3}$ Pico, AOD-TH2 manufactured by Aidenshi Co., Ltd., Nasushiobara, Japan) and dropped onto the fabric at the same position as the UV spot.

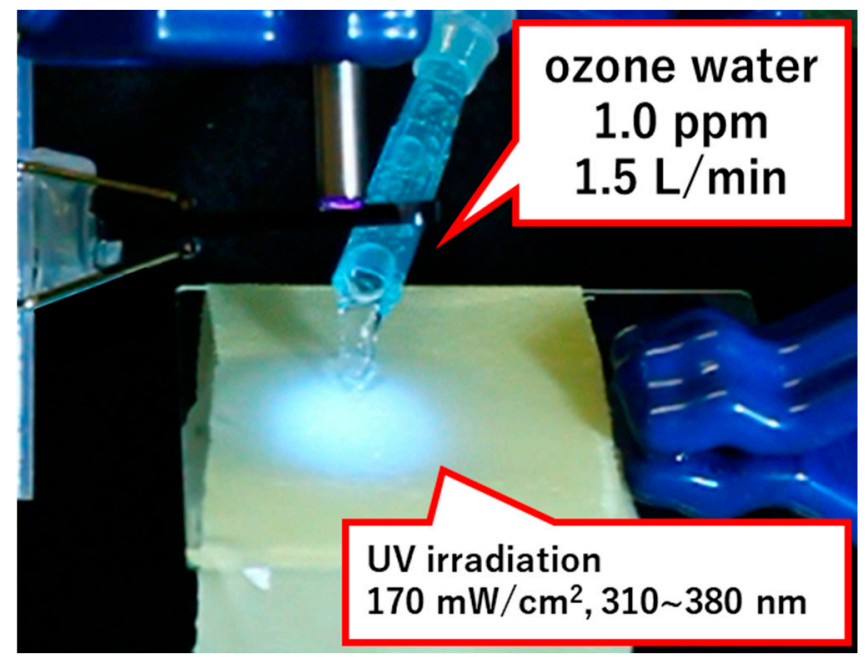

Figure 14. Photograph of a bleaching experiment. The fabric sample was set on a glass plate. Water containing electrochemically generated ozone was dropped onto the fabric, and the sample was irradiated with ultraviolet (UV) light.

The rongalite treatment was carried out by the dipping method. The sample after AOP treatment was immersed in a $0.5 \mathrm{wt} \%$ rongalite aqueous solution for $1 \mathrm{~h}$, then drained and dried on a hot plate at 
$200{ }^{\circ} \mathrm{C}$ for $1 \mathrm{~min}$. Figure 15 shows photographs and a schematic of the measurement of the amount of $\mathrm{OH}$ radicals in the aqueous ozone under UV irradiation. It is well known that $\mathrm{OH}$ radicals are generated by AOP treatment with aqueous ozone and UV irradiation $[15,16,19,20]$. In this study, the $\mathrm{OH}$ radical concentration in the ozone solution during AOP treatment was measured using a disodium terephthalate chemical probe $[17,18]$. As shown in Figure 15, aqueous ozone irradiated with UV was collected and then mixed with disodium terephthalate (NaTA, TCI Co., Ltd., Tokyo, Japan) until completely dissolved. Then, while irradiating the solution with UV light, the generated fluorescence was detected. An SEC-2000-UV/VIS Spectrometer manufactured by ALS Co., Ltd. (Tokyo, Japan) was used for UV light generation and fluorescence detection. Disodium terephthalate, used as an indicator, reacts with $\mathrm{OH}$ radicals in aqueous solution to produce 2-hydroxyterephthalic acid, which fluoresces at $425 \mathrm{~nm}$ under UV irradiation, allowing quantification of the generated $\mathrm{OH}$ radicals.

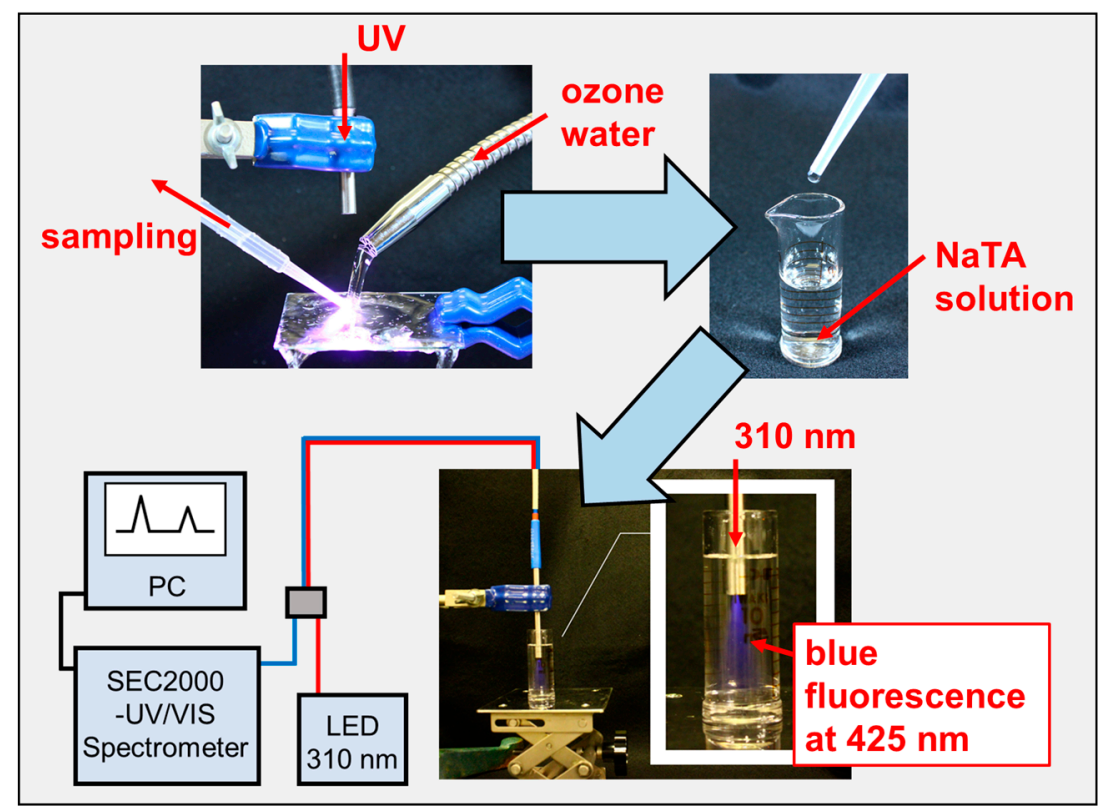

Figure 15. Photographs and schematic of $\mathrm{OH}$ radical quantification by fluorescence spectroscopy.

\section{Conclusions}

In this paper, we reported a two-step fabric treatment method based on AOP treatment using aqueous ozone and UV irradiation with rongalite treatment. The AOP process removed coloured components in fabric via decomposition with active oxygen species (ozone and the $\mathrm{OH}$ radicals generated in aqueous solution). The $\mathrm{OH}$ radical concentration in the aqueous solution was measured by a chemical probe, which can easily and quickly measure $\mathrm{OH}$ radicals on the spot, and it is applicable to industrial-scale process control. The reflectance spectra of the fabric samples revealed an increase in bleaching with increasing treatment time, and, after $60 \mathrm{~min}$ for cotton and $120 \mathrm{~min}$ for linen, bleaching comparable to that of the conventional method was achieved. In addition, we confirmed that AOP treatment is suitable for decomposing waxes and oils contained in the fabric before scouring. Therefore, this AOP process can replace conventional scouring and bleaching processes. Furthermore, we succeeded in preventing colour reversion by reducing cellulose oxidised by the AOP treatment with inexpensive rongalite. The AOP + rongalite treatment for fabrics is attractive because it produces little waste and consumes little energy compared with the conventional method. Thus, this method is a promising alternative to conventional bleaching in natural fibre processing.

Author Contributions: K.H., T.O., K.M., Y.I., T.N. and N.K. participated in the study design and conducted the study; K.H., T.O. and Y.T. collected and analysed the data. K.H. wrote the manuscript. All authors have read and agreed to the published version of the manuscript. 
Funding: This research received no external funding.

Acknowledgments: We are grateful to Nisshinbo Textile Inc. for preparing the fabrics. We are also grateful to Ayato Koibuchi and Kosuke Miura (Nagaoka University of Technology) for help with the experiments and for insightful discussion. We would like to thank Editage (www.editage.com) for English language editing.

Conflicts of Interest: The authors declare no conflict of interest.

\section{References}

1. Abdel-Halim, E.S. An effective redox system for bleaching cotton cellulose. Carbohydr. Polym. 2012, 90, 316-321. [CrossRef] [PubMed]

2. Hebeish, A.; Hashem, M.; Shaker, N.; Ramadan, M.; El-Sadek, B.; Hady, M.A. New development for combined bioscouring and bleaching of cotton-based fabrics. Carbohydr. Polym. 2009, 78, 961-972. [CrossRef]

3. Lim, S.-H.; Gürsoy, N.Ç.; Hauser, P.; Hinks, D. Performance of a new cationic bleach activator on a hydrogen peroxide bleaching system. Coloration Technol. 2004, 120, 114-118. [CrossRef]

4. Shafie, A.E.; Fouda, M.M.G.; Hashem, M. One-step process for bio-scouring and peracetic acid bleaching of cotton fabric. Carbohydr. Polym. 2009, 78, 302-308. [CrossRef]

5. Yao, Y.; Kubota, Y.; Murakami, T.; Ochiai, T.; Ishiguro, H.; Nakata, K.; Fujishima, A. Electrochemical Inactivation Kinetics of Boron-Doped Diamond Electrode on Waterborne Pathogens. J. Water Health 2011, 9, 534-543. [CrossRef] [PubMed]

6. Ochiai, T.; Tago, S.; Hayashi, M.; Hirota, K.; Kondo, T.; Satomura, K.; Fujishima, A. Boron-doped diamond powder (BDDP)-based polymer composites for dental treatment using flexible pinpoint electrolysis unit. Electrochem. Commun. 2016, 68, 49-53. [CrossRef]

7. Ouchi, A. Photochemical Reactions and their Application to Textile Processing. Oleoscience 2015, 15, 455-460. [CrossRef]

8. Abdel-Halim, E.S.; Al-Deyab, S.S. One-step bleaching process for cotton fabrics using activated hydrogen peroxide. Carbohydr. Polym. 2013, 92, 1844-1849. [CrossRef]

9. Li, Q.; Ni, L.; Wang, J.; Quan, H.; Zhou, Y. Establishing an ultrasound-assisted activated peroxide system for efficient and sustainable scouring-bleaching of cotton/spandex fabric. Ultrason. Sonochem. 2020, 68, 105220. [CrossRef]

10. Perincek, S.; Bahtiyari, I.; Korlu, A.; Duran, K. New Techniques in Cotton Finishing. Text. Res. J. 2009, 79, 121-128. [CrossRef]

11. Perincek, S.D.; Duran, K.; Korlu, A.E.; Bahtiyari, İ.M. An Investigation in the Use of Ozone Gas in the Bleaching of Cotton Fabrics. Ozone Sci. Eng. 2007, 29, 325-333. [CrossRef]

12. Piccoli, H.H.; Ulson de Souza, A.A.; Ulson de Souza, S.M.A.G. Bleaching of Knitted Cotton Fabric Applying Ozone. Ozone Sci. Eng. 2015, 37, 170-177. [CrossRef]

13. Hashem, M.; Taleb, M.A.; El-Shall, F.N.; Haggag, K. New prospects in pretreatment of cotton fabrics using microwave heating. Carbohydr. Polym. 2014, 103, 385-391. [CrossRef] [PubMed]

14. Farooq, A.; Ali, S.; Abbas, N.; Fatima, G.A.; Ashraf, M.A. Comparative performance evaluation of conventional bleaching and enzymatic bleaching with glucose oxidase on knitted cotton fabric. J. Clean. Prod. 2013, 42, 167-171. [CrossRef]

15. He, Y.; Wang, X.; Xu, J.; Yan, J.; Ge, Q.; Gu, X.; Jian, L. Application of integrated ozone biological aerated filters and membrane filtration in water reuse of textile effluents. Bioresour. Technol. 2013, 133, 150-157. [CrossRef]

16. Buffle, M.-O.; Schumacher, J.; Meylan, S.; Jekel, M.; von Gunten, U. Ozonation and Advanced Oxidation

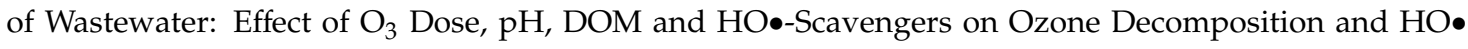
Generation. Ozone Sci. Eng. 2006, 28, 247-259. [CrossRef]

17. Hayashi, H.; Akamine, S.; Ichiki, R.; Kanazawa, S. Comparison of OH radical concentration generated by underwater discharge using two methods. Int. J. Plasma Environ. Sci. Technol. 2016, 10, 24-28.

18. Kanazawa, S.; Kawano, H.; Watanabe, S.; Furuki, T.; Akamine, S.; Ichiki, R.; Ohkubo, T.; Kocik, M.; Mizeraczyk, J. Observation of $\mathrm{OH}$ radicals produced by pulsed discharges on the surface of a liquid. Plasma Sources Sci. Technol. 2011, 20, 034010. [CrossRef]

19. Sharma, V.K.; Graham, N.J.D. Oxidation of Amino Acids, Peptides and Proteins by Ozone: A Review. Ozone Sci. Eng. 2010, 32, 81-90. [CrossRef] 
20. Ikehata, K.; Jodeiri Naghashkar, N.; Gamal El-Din, M. Degradation of Aqueous Pharmaceuticals by Ozonation and Advanced Oxidation Processes: A Review. Ozone: Sci. Eng. 2006, 28, 353-414. [CrossRef]

21. Matsumi, Y.; Comes, F.J.; Hancock, G.; Hofzumahaus, A.; Hynes, A.J.; Kawasaki, M.; Ravishankara, A.R. Quantum yields for production of $\mathrm{O}\left({ }^{1} D\right)$ in the ultraviolet photolysis of ozone: Recommendation based on evaluation of laboratory data. J. Geophys. Res. Atmos. 2002, 107, 1-12. [CrossRef]

22. Attri, P.; Kim, Y.H.; Park, D.H.; Park, J.H.; Hong, Y.J.; Uhm, H.S.; Kim, K.-N.; Fridman, A.; Choi, E.H. Generation mechanism of hydroxyl radical species and its lifetime prediction during the plasma-initiated ultraviolet (UV) photolysis. Sci. Rep. 2015, 5, 9332. [CrossRef] [PubMed]

23. Goswami, K.K. Bleaching of linen (Linum usitatissimum). Indian J. Fibre Texlie Res. 1993, 18, 82-86.

24. Yui, Y.; Tanaka, C.; Isogai, A. Functionalization of Cottton Fabrics by TEMPO-Mediated Oxidation. SENI GAKKAISHI 2013, 69, 222-228. [CrossRef]

25. Arooj, F.; Ahmad, N.; Shaikh, I.A.; Chaudhry, M.N. Application of ozone in cotton bleaching with multiple reuse of a water bath. Text. Res. J. 2013, 84, 527-538. [CrossRef]

26. Japanese Standards Association. JIS Z 8722 Methods of Colour Measurement-Reflecting and Transmitting Objects; Japanese Standards Association: Tokyo, Japan, 2009.

27. Ochiai, T.; Aoki, D.; Saito, H.; Akutsu, Y.; Nagata, M. Analysis of Adsorption and Decomposition of Odour and Tar Components in Tobacco Smoke on Non-Woven Fabric-Supported Photocatalysts. Catalysts 2020, 10, 304. [CrossRef]

Publisher's Note: MDPI stays neutral with regard to jurisdictional claims in published maps and institutional affiliations. 